\title{
Human Monocytic Ehrlichiosis, Mexico City, Mexico
}

\author{
Virginia E. Alcántara-Rodríguez, ${ }^{1}$ Sokani Sánchez-Montes, ${ }^{1}$ Hugo Contreras, Pablo Colunga-Salas, ${ }^{1}$
} Lauro Fierro-Flores, Sergio Avalos, Francisco Rodríguez-Rangel, Ingeborg Becker, David H. Walker

Little information is available about human infections by the members of the genus Ehrlichia in Mexico. Only 2 species, Ehrlichia canis and E. chaffensis, are known to cause disease in this country. We report a fatal case of human monocytic ehrlichiosis in Mexico City in a man who was homeless.

$\mathrm{T}$ he genus Ehrlichia contains 6 species of obligately intracytoplasmic bacteria that have major roles in human and veterinary medicine. These bacteria can cause ehrlichiosis, an emerging zoonoses transmitted mainly by bites of several hard tick species of the genera Amblyomma, Ixodes, and Rhipicephalus (1). In the Americas, the most relevant species that involves public health is Ehrlichia chaffeensis, the etiologic agent of human monocytic ehrlichiosis, an acute disease characterized by fever, thrombocytopenia, leukopenia, alterations of coagulation, and hepatic and neurologic involvement; systemic complications can lead to death in $3 \%$ of case-patients $(1,2)$.

Little is known about Ehrlichia infections in Mexico. A human case was reported in the $\mathrm{Yu}$ catan Peninsula during 1999 in a male patient who had fever, anorexia, lymphadenopathy, cutaneous bleeding, and sore throat. Peripheral blood morulae, PCR detection of E. chaffeensis, and anemia were also reported (3). Subsequently, a case of $E$. canis infection was detected in the coastal state of Oaxaca in a veterinary stylist who had close contact with dogs (4). A study published in 2016 reported a female resident of the state of Mexico who had

Author affiliations: Secretaría de Salud de la Ciudad de México, Mexico City, Mexico (V.E. Alcántara-Rodríguez, H. Contreras,

L. Fierro-Flores, S. Avalos, F. Rodríguez-Rangel); Universidad Veracruzana, Veracruz, Mexico (S. Sánchez-Montes); Universidad Nacional Autónoma de México, Mexico City (S. Sánchez-Montes, P. Colunga-Salas, I. Becker); University of Texas Medical Branch, Galveston, Texas, USA (D.H. Walker)

DOI: https://doi.org/eid2612.200520 fever, thrombocytopenia, and alteration of liver enzyme levels and died after a long hospitalization (5). We report a fatal case of human monocytic ehrlichiosis in Mexico City, Mexico.

\section{The Study}

On March 3, 2017, a 35-year-old man who was homeless (resident in Mexico City for 4 years) was admitted to the Emergency Department in the General Hospital of Xoco of the Ministry of Health of Mexico City because of trauma after a fall of $6 \mathrm{~m}$ from a bridge as a result of a suicide attempt. At admission, no lesions were detected in internal organs; a transtrochanteric fracture of the left femoral head was surgically repaired without complications. However, the patient had profuse bleeding during the surgical procedure, for which it was necessary to provide multiple blood transfusions. The blood units came from resident donors of Mexico City and the neighboring state of Mexico. In the postoperative period, the patient remained hospitalized for 65 days, during which behavioral alterations with several psychotic periods developed. He also had febrile episodes that evolved to a torpid state.

Routine laboratory analyses (blood count, blood chemistry, and serologic studies for infectious diseases) were performed. Because the patient was homeless and had persistent febrile episodes and dysfunction of the coagulation system, a possible infection by a rickettsial agent or Bartonella spp. was suspected because Bartonella quintana has been detected previously in human lice from persons who were homeless in Mexico City (6). For this reason $5 \mathrm{~mL}$ of whole blood was obtained, stored in EDTA, and processed for DNA extraction by using the QIAamp DNA Mini Kit (QIAGEN, https://www.qiagen.com) according to the manufacturer's instructions. Blood was then examined for Bartonella, Ehrlichia/Anaplasma, and Rickettsia spp. by amplifying fragments of the

\footnotetext{
${ }^{1}$ These authors contributed equally to this article.
} 
gltA, rrs, and sca5, genes and using primers and PCR conditions specified (7-9). Positive controls (E. canis [GenBank accession no. MG917715], B. vinsonii [KT326174], and Rickettsia amblyommatis [KX363842) DNA]) were also included.

On April 27, 2017, antibodies against Proteus OX-19 at a titer of 1:320, leukocytosis, thrombocytosis, lymphopenia, anemia, hypoalbuminemia, and coagulation and liver enzyme alterations were reported (Table, https://wwwnc.cdc.gov/EID/ article/26/12/20-0520-T1.htm). The patient was given a diagnosis of septic shock and urosepsis and died on day 63 of hospitalization.

During hospitalization, leukocytosis developed, which might have been associated with the multiple trauma. The patient initially had a platelet count within the reference range, but thrombocytosis developed, and the platelet count increased to 850,000/ $\mu \mathrm{L}$. However, with persistent leukocytosis, the platelet count dropped, and thrombocytopenia $(108,000 /$ $\mu \mathrm{L}$ ) developed shortly before death.

Total serum protein and albumin concentrations at admission were within reference ranges, but dur- ing hospitalization they decreased, as would be expected for a diagnosis of ehrlichiosis. Alterations in liver enzyme levels and coagulation times also developed. Levels of alanine aminotransferase (ALT) and aspartate aminotransferase also increased after admission; ALT showed the largest increase. The level of $\gamma$-glutamyl transpeptidase increased by $>10$ times over its reference value (Table). The increase in the level of ALT could be related to hepatic alterations linked to ehrlichiosis.

Necropsy showed hepatosplenomegaly and pleural effusions. Molecular assays did not detect Bartonella or Rickettsia spp., but they did detect Ehrlichia/ Anaplasma spp. when primers Ehr1/Ehr2 were used. We isolated a 400-bp fragment of the 16S rRNA gene, which showed $99 \%$ identity with that of the E. chaffensis strain Arkansas. In addition, a 500-bp fragment of the $d s b$ gene (present only in the members of the genus Ehrlichia) was amplified (10) and showed 100\% identity with the sequence of E. chaffensis strain Arkansas.

Phylogenetic analysis of the isolated sequences grouped them with sequences of 2 strains of $E$. chaffensis (strain Arkansas and West Paces) detected

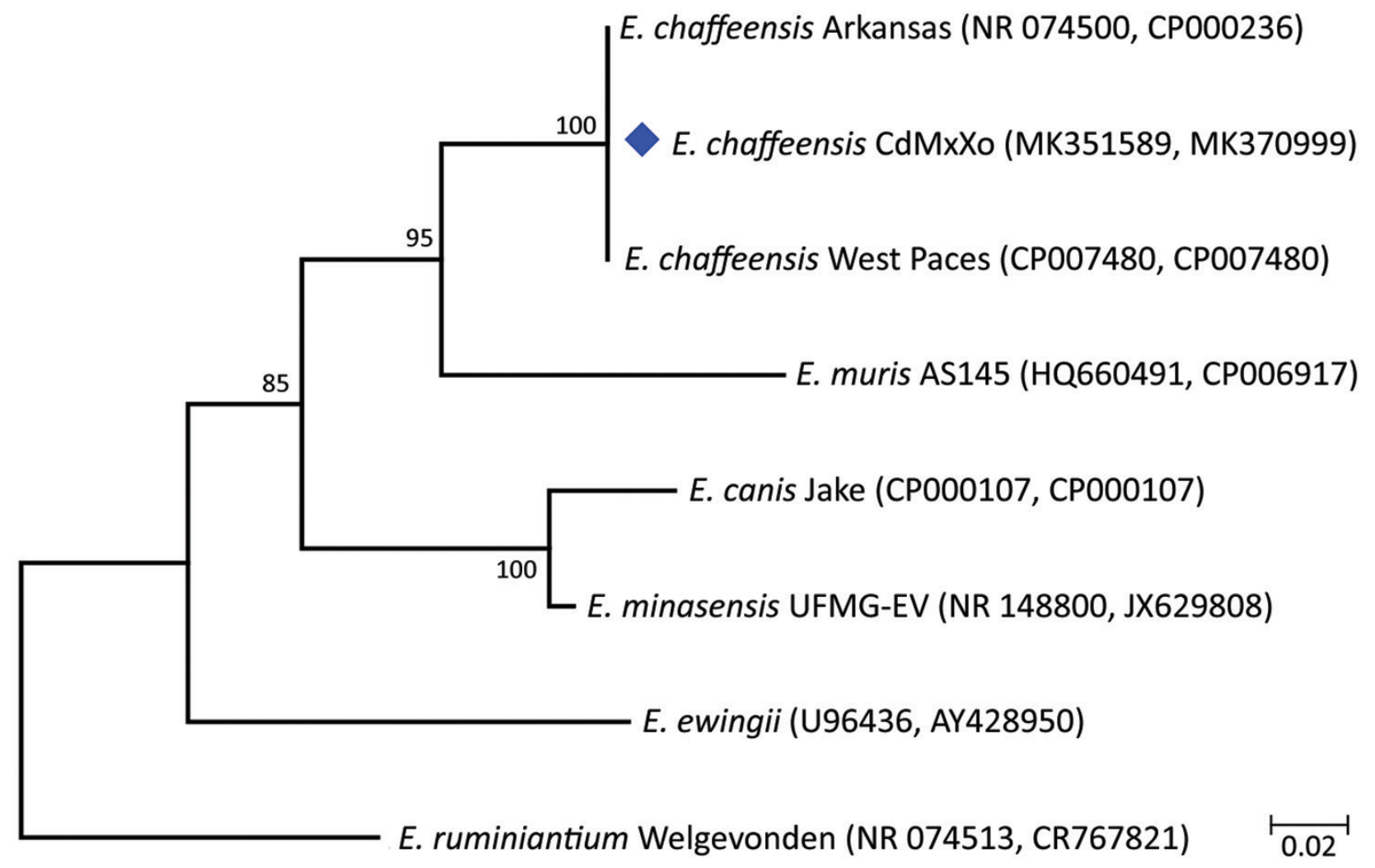

Figure. Maximum-likelihood phylogenetic tree for Ehrlichia chaffensis from a patient with human monocytic ehrlichiosis, Mexico City, Mexico (blue diamond), and reference sequences. The tree was generated by using concatenated fragments of 16S rRNA and dsb genes in an 850-bp alignment. GenBank accession numbers are indicated in parentheses. Numbers along branches are bootstrap values. Scale bar indicates nucleotide substitutions per site. 
in the United States; these sequences had a bootstrap value of 99. The sequences we obtained were deposited in GenBank under accession numbers MK351589 and MK370999 (Figure).

\section{Conclusions}

Ehrlichioses represent systemic infections that can cause damage to different organs and systems, affecting the liver, meninges, brain, heart, and lungs. Because the pathophysiology of this disease is not well established, the findings obtained by necropsy are useful. During his hospitalization, the patient acquired some bacterial infections, which could explain the paradox that he initially had thrombocytosis and leukocytosis instead of thrombocytopenia and leukopenia, as would be expected for ehrlichiosis. Leukopenia and thrombocytopenia are present in $>50 \%$ of patients given a diagnosis of E. chaffeensis infection (5).

The patient might have been infected by blood transfusion because the long period between hospital admission and detection of thrombocytopenia is compatible with the incubation period for infection with $E$. chaffeensis. The patient received multiple blood transfusions from donors in Mexico City and the state of Mexico; in this state, a fatal case of ehrlichiosis caused by blood transfusion has been reported (5). A study in Costa Rica reported a large number of $E$. canis-infected healthy blood donors (11), and a study in the United States reported a patient who was infected by blood transfusion containing E. ewingii (12). More recently, a potential case of transfusion-transmitted human monocytic ehrlichiosis was reported in a 59-year-old woman in the United States after she received a blood stem cell transplant (13).

Although this possibility is less likely, it cannot be ruled out that ehrlichiosis could be acquired by tick bite. E. chaffeensis was previously detected in 3 hard tick species (Amblyomma americanum, A. mixtum, and Rhipicephalus sanguineus sensu 1ato) (14) in Mexico. Only the lone star tick (A. americanum) has been implicated as a primary vector of this pathogen in the United States; however, its presence in Mexico has only been recorded restricted to the Nearctic region (15). Conversely, no studies demonstrate the role of the other 2 tick species as potential vectors of this pathogen or whether DNA of this pathogen came from an infected host from which these ticks fed.

For this reason, it is essential to perform systematic surveillance of this and other tick-borne pathogens in blood donors in Mexico. Studies should also be conducted with questing ticks to identify the risk to which the population is exposed and establish the actual distribution of the pathogen.

\section{About the Author}

Dr. Alcántara-Rodríguez is chief of the Unit of Epidemiologic Surveillance for hospitals of the Health Ministry, Mexico City, Mexico. Her primary research interest is rickettsioses.

\section{References}

1. Cabezas-Cruz A, Zweygarth E, Vancová M, Broniszewska M, Grubhoffer L, Passos LM, et al. Ehrlichia minasensis sp. nov., isolated from the tick Rhipicephalus microplus. Int J Syst Evol Microbiol. 2016;66:1426-30. https:/ / doi.org/10.1099/ ijsem.0.000895

2. Geier C, Davis J, Siegel M. Severe human monocytic ehrlichiosis presenting with altered mental status and seizures. BMJ Case Rep. 2016;2016:bcr2016215967. https://doi.org/10.1136/bcr-2016-215967

3. Gongóra-Biachi RA, Zavala-Velázquez J, Castro-Sansores CJ, González-Martínez P. First case of human ehrlichiosis in Mexico. Emerg Infect Dis. 1999;5:481. https:/ / doi.org/ 10.3201/eid0503.990327

4. Beatriz Silva A, Pina Canseco S, Gabriel de la Torre MP, Mayoral Silva A, Mayoral MÁ, Pérez-Campos Mayoral L, et al. Asymptomatic human infection from contact with dogs: a case of human ehrlichiosis [in Spanish]. Gac Med Mex. 2014;150:171-4.

5. Sosa-Gutierrez CG, Solorzano-Santos F, Walker DH, Torres J, Serrano CA, Gordillo-Perez G. Fatal monocytic ehrlichiosis in woman, Mexico, 2013. Emerg Infect Dis. 2016;22:871-4. https://doi.org/10.3201/eid2205.151217

6. Alcántara V, Rolain JM, Eduardo AG, Raul MJ, Raoult D. Molecular detection of Bartonella quintana in human body lice from Mexico City. Clin Microbiol Infect. 2009;15(Suppl 2):93-4. https:// doi.org/10.1111/j.1469-0691.2008.02176.x

7. Norman AF, Regnery R, Jameson P, Greene C, Krause DC. Differentiation of Bartonella-like isolates at the species level by PCR-restriction fragment length polymorphism in the citrate synthase gene. J Clin Microbiol. 1995;33:1797-803. https:// doi.org/10.1128/JCM.33.7.1797-1803.1995

8. Roux V, Raoult D. Phylogenetic analysis of members of the genus Rickettsia using the gene encoding the outer-membrane protein $\mathrm{rOmpB}(\mathrm{ompB})$. Int J Syst Evol Microbiol. 2000;50:1449-55. https://doi.org/10.1099/ 00207713-50-4-1449

9. Murphy DS, Lee X, Larson SR, Johnson DK, Loo T, Paskewitz SM. Prevalence and distribution of human and tick infections with the Ehrlichia muris-like agent and Anaplasma phagocytophilum in Wisconsin, 2009-2015. Vector Borne Zoonotic Dis. 2017;17:229-36. https:/ / doi.org/10.1089/vbz.2016.2055

10. Doyle CK, Labruna MB, Breitschwerdt EB, Tang YW, Corstvet RE, Hegarty BC, et al. Detection of medically important Ehrlichia by quantitative multicolor TaqMan real-time polymerase chain reaction of the $d s b$ gene. J Mol Diagn. 2005;7:504-10. https://doi.org/10.1016/ S1525-1578(10)60581-8

11. Bouza-Mora L, Dolz G, Solórzano-Morales A, Romero-Zuñiga JJ, Salazar-Sánchez L, Labruna MB, et al. Novel genotype of Ehrlichia canis detected in samples of human blood bank donors in Costa Rica. Ticks Tick Borne Dis. 2017;8:36-40. https:/ / doi.org/10.1016/ j.ttbdis.2016.09.012

12. Regan J, Matthias J, Green-Murphy A, Stanek D, Bertholf M, Pritt BS, et al. A confirmed Ehrlichia ewingii 
infection likely acquired through platelet transfusion. Clin Infect Dis. 2013;56:e105-7. https://doi.org/10.1093/cid/cit177

13. Mah A, Viola GM, Ariza Heredia E, Rezvani K, Kebriaei P, Bhatti MM, et al. Graft loss attributed to possible transfusion-transmitted ehrlichiosis following cord blood stem cell transplant. Transpl Infect Dis. 2018;20:e12899. https://doi.org/10.1111/tid.12899

14. Sosa-Gutierrez CG, Vargas-Sandoval M, Torres J, Gordillo-Pérez G. Tick-borne rickettsial pathogens in questing ticks, removed from humans and animals in Mexico. J Vet Sci. 2016;17:353-60. https:/ / doi.org/10.4142/ jvs.2016.17.3.353

15. Guzmán-Cornejo C, Robbins RG, Guglielmone AA, Montiel-Parra G, Pérez TM. The Amblyomma (Acari: Ixodida:
Ixodidae) of Mexico: identification keys, distribution and hosts. Zootaxa. 2011;2998:16-38 [cited 2020 Sep 8]. https://www.mapress.com/j/zt/article/view/ zootaxa.2998.1.2

Address for correspondence: Virginia E. Alcántara Rodríguez, Unidad Departamental de Vigilancia Epidemiológica, Dirección General de Prestación de Servicios Médicos y Urgencias de la Secretaria de Salud de la Ciudad de México, SEDESA, Torre Insignia Avenida Insurgentes Norte No 423, Conjunto Urbano Nonoalco-Tlateloco, Alcaldía Cuauhtémoc, CP 06920 Ciudad de México, Mexico; email: vealcant55@yahoo.com

\section{April 2020}

\section{Vectorborne Infections}

- Stemming the Rising Tide of HumanBiting Ticks and Tickborne Diseases, United States

- Ecology and Epidemiology of Tickborne Pathogens, Washington, USA, 2011-2016

- Imported Arbovirus Infections in Spain, 2009-2018

- Decreased Susceptibility to Azithromycin in Clinical Shigella Isolates Associated with HIV and Sexually Transmitted Bacterial Diseases, Minnesota, USA, 2012-2015

- High Incidence of Active Tuberculosis in Asylum Seekers from Eritrea and Somalia in the First 5 Years after Arrival in the Netherlands

- Severe Dengue Epidemic, Sri Lanka, 2017

- Severe Fever with Thrombocytopenia Syndrome, Japan, 2013-2017

- Comprehensive Profiling of Zika Virus Risk with Natural and Artificial Mitigating Strategies, United States

- Genomic Insight into the Spread of Meropenem-Resistant Streptococcus pneumoniae Spain-ST81, Taiwan

- Isolation of Drug-Resistant Gallibacterium anatis from Calves with Unresponsive Bronchopneumonia, Belgium

- Guaroa Virus and Plasmodium vivax Co-Infections, Peruvian Amazon

- Intensified Short Symptom Screening Program for Dengue Infection during Pregnancy, India

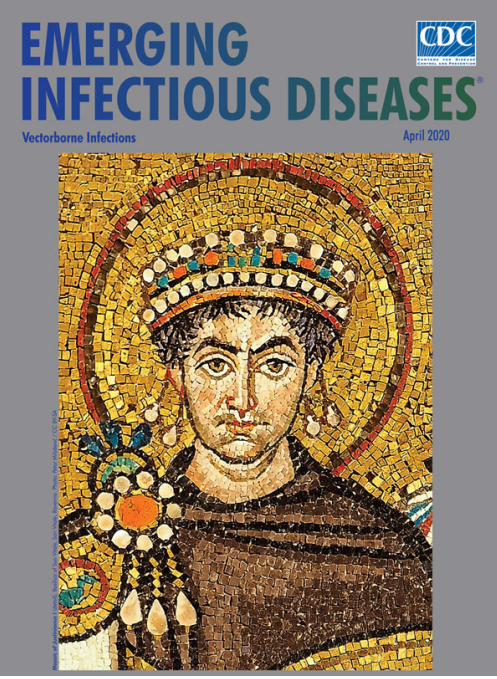

- Prevalence of Antibodies to CrimeanCongo Hemorrhagic Fever Virus in Ruminants, Nigeria, 2015

- Recurrent Herpes Simplex Virus 2 Lymphocytic Meningitis in Patient with IgG Subclass 2 Deficiency

- Health-Related Quality of Life after Dengue Fever, Morelos, Mexico, 2016-2017

- Person-to-Person Transmission of Andes Virus in Hantavirus Pulmonary Syndrome, Argentina, 2014

- Ebola Virus Neutralizing Antibodies in Dogs from Sierra Leone, 2017

- Outbreak of Dirkmeia churashimaensis Fungemia in a Neonatal Intensive Care Unit, India
- Rift Valley Fever Outbreak, Mayotte, France, 2018-2019

- Crimean-Congo Hemorrhagic Fever Virus in Humans and Livestock, Pakistan, 2015-2017

- Detection of Zoonotic Bartonella Pathogens in Rabbit Fleas, Colorado, USA

- Human-to-Human Transmission of Monkeypox Virus, United Kingdom, October 2018

- Whole-Genome Analysis of Salmonella enterica Serovar Enteritidis Isolates in Outbreak Linked to Online Food Delivery, Shenzhen, China, 2018

- Pruritic Cutaneous Nematodiasis Caused by Avian Eyeworm Oxyspirura Larvae, Vietnam

- Novel Rapid Test for Detecting Carbapenemase

- Arthritis Caused by MRSA CC398 in a Patient without Animal Contact, Japan

- Detection of Rocio Virus SPH 34675 during Dengue Epidemics, Brazil, 2011-2013

- Epidemiology of Lassa Fever and Factors Associated with Deaths, Bauchi State, Nigeria, 2015-2018

- Plague Epizootic Dynamics in Chipmunk Fleas, Sierra Nevada Mountains, California, USA, 2013-2015

- Knowledge of Infectious Disease Specialists Regarding Aspergillosis Complicating Influenza, United States 